This item was submitted to Loughborough's Research Repository by the author.

Items in Figshare are protected by copyright, with all rights reserved, unless otherwise indicated.

\title{
Differentiation of ankle sprain motion and common sporting motion by ankle inversion velocity
}

\section{PLEASE CITE THE PUBLISHED VERSION}

http://dx.doi.org/10.1016/j.jbiomech.2010.03.029

\section{PUBLISHER}

(C) Elsevier

\section{VERSION}

AM (Accepted Manuscript)

\section{PUBLISHER STATEMENT}

This work is made available according to the conditions of the Creative Commons Attribution-NonCommercialNoDerivatives 4.0 International (CC BY-NC-ND 4.0) licence. Full details of this licence are available at: https://creativecommons.org/licenses/by-nc-nd/4.0/

\section{LICENCE}

CC BY-NC-ND 4.0

\section{REPOSITORY RECORD}

Chu, Vikki Wing-Shan, Daniel Tik-Pui Fong, Yue-Yan Chan, Patrick Shu-Hang Yung, Kwai-Yau Fung, and KaiMing Chan. 2019. "Differentiation of Ankle Sprain Motion and Common Sporting Motion by Ankle Inversion Velocity”. figshare. https://hdl.handle.net/2134/21073. 


\begin{tabular}{|c|c|c|c|}
\hline Title & \multicolumn{3}{|c|}{$\begin{array}{l}\text { Differentiation of ankle sprain motion and common sporting motion by } \\
\text { ankle inversion velocity }\end{array}$} \\
\hline Article type & \multicolumn{3}{|c|}{ Short communication } \\
\hline Authors & \multicolumn{3}{|c|}{$\begin{array}{l}\text { Vikki Wing-Shan Chu }^{1,2} \text {, Daniel Tik-Pui } \text { FONG }^{1,2} \text {, Yue-Yan Chan } \\
\text { Patrick Shu-Hang YUNG } \\
\text { PUN, }\end{array}$} \\
\hline Affiliations & \multicolumn{3}{|c|}{$\begin{array}{l}\text { Department of Orthopaedics and Traumatology, Prince of Wales } \\
\text { Hospital, Faculty of Medicine, The Chinese University of Hong Kong, } \\
\text { Hong Kong, China }^{1} \\
\text { The Hong Kong Jockey Club Sports Medicine and Health Sciences } \\
\text { Centre, Faculty of Medicine, The Chinese University of Hong Kong, } \\
\text { Hong Kong, China }{ }^{2} \\
\text { Department of Orthopaedics and Traumatology, Alice Ho Miu Ling } \\
\text { Nethersole Hospital, Hong Kong, China }\end{array}$} \\
\hline Keywords & \multicolumn{3}{|c|}{ Ankle sprain, biomechanics, kinematics, supination } \\
\hline Total words & 1499 & Words in abstract & 233 \\
\hline \multicolumn{4}{|c|}{ Correspondence author } \\
\hline Telephone & $(852) 26323535$ & Facsimile & $(852) 26463020$ \\
\hline E-mail & \multicolumn{3}{|c|}{ dfong@ort.cuhk.edu.hk } \\
\hline
\end{tabular}

1

2 


\section{Abstract}

4 This study investigated the ankle inversion and inversion velocity between various

5 common motions in sports and simulated sprain motion, in order to provide a

6 threshold for ankle sprain risk identification. The experiment was composed of two

7 parts: Firstly, ten male subjects wore a pair of sport shoes and performed ten trials of

8 running, cutting, jump-landing and stepping-down motions. Secondly, five subjects

9 performed five trials of simulated sprain motion by a supination sprain simulator. The

10 motions were analyzed by an eight-camera motion capture system at $120 \mathrm{~Hz}$. A force

11 plate was employed to record the vertical ground reaction force and locate the foot

12 strike time for common sporting motions. Ankle inversion and inversion velocity were

13 calculated by a standard lower extremity biomechanics calculation procedure. Profiles

14 of vertical ground reaction force, ankle inversion angle and ankle inversion velocity

15 were obtained. Results suggested that the ankle was kept in an everted position during

16 the stance. The maximum ankle inversion velocity ranged from 22.5 to $85.1 \mathrm{deg} / \mathrm{s}$ and

$17 \quad 114.0$ to $202.5 \mathrm{deg} / \mathrm{s}$ for the four tested motions and simulated sprain motion

18 respectively. Together with the ankle inversion velocity reported in the injury case

19 (623 deg/s), a threshold of ankle inversion velocity of $300 \mathrm{deg} / \mathrm{s}$ was suggested for the

20 identification of ankle sprain. The information obtained in this study can serves as a

21 basis for the development of an active protection apparatus for reducing ankle sprain

22 injury.

23

24 Introduction

25 Ankle is the most popular injured body site in sport (Fong et al., 2007a). Among ankle

26 injury, 80\% were ligamentous sprain (Fong et al., 2009a). After acute ligament rupture,

$2720 \%$ of patients develop chronic ankle instability. It can be either mechanical with 
structural ligament lesion or functional with loss of the neuromuscular control (Krips et al., 2006). Over the years, different approaches have been employed to prevent ankle sprain injury. However, a recent epidemiological study has revealed that ankle sprain is still a prevalent sports related injury, as it has been shown to account for $14 \%$ of all attendances at an accident and emergency department (Fong et al., 2008) - this suggests that there is the potential for new ideas regarding ankle sprain prevention in sports.

Recently, there is an innovative attempt in designing an intelligent sprain free sport shoe for preventing ankle sprain injury (Chan, 2006). Before initiating an active correction mechanism in case of an ankle sprain, the shoe system measures and monitors ankle joint biomechanical changes in order to recognize if it is approaching the onset of an ankle sprain. In order to do so a system to identify sprain motion should be first developed. Ankle kinematics of common sporting motion and sprain motion can provide information to develop such a system. Therefore, this study focuses on the investigation of the kinematic, i.e. ankle inversion angle and velocity of common sporting motions and simulated sprain motion. Together with the kinematic data of an accidental ankle sprain injury event reported in a laboratory (Fong et al., 2009b), the findings provide information to determine a threshold to 7 identify an ankle sprain injury from common sporting motions. With the suggested threshold, an in-shoe alarm system to monitor the ankle sprain injury risk could be 9 devised with a recent advanced method to measure ankle inversion and inversion velocity with two tiny inertial and magnetic sensors (O’Donovan et al., 2007). 
Ten recreational male athletes were recruited (age $=23.4 \pm 3.0 \mathrm{yr}$, height $=1.73 \pm$ $0.03 \mathrm{~m}$, body mass $=65.1 \pm 9.7 \mathrm{~kg}$, foot length $=255-260 \mathrm{~mm})$. Each subject wore a pair of cloth sport shoes (Fong et al., 2007b) and performed ten trials of running, 45-degree cutting, vertical jump-landing and stepping-down (from a block) motions in a random sequence in a motion biomechanics laboratory. Subjects were asked to perform the motions with their full effort and own landing strategy. These motions were chosen because they are common in various kinds of sports. In each trial, the subject performed the motion and stepped on a force plate (Advanced Mechanical moment when vertical ground reaction force exceeded 20N (Fong et al., 2007b). mass $=63.7 \pm 9.7 \mathrm{~kg}$ ) participated in the test. Each subject wore a pair of cloth sport shoes performed simulated supination sprain motions in different degree of supination on the supination sprain simulator (Chan et al., 2008). When the fall platform is set at $0^{\circ}$ or $90^{\circ}$, rather pure inversion or planter flexion motion is provided respectively. Five

71 angles $\left(0^{\circ}, 23^{\circ}, 45^{\circ}, 67^{\circ}\right.$ and $\left.90^{\circ}\right)$ were used in the test. In each angles, five trials were 72 performed.

74 The university ethics committee approved the study. Five reflective skin markers were attached at the position of fifth metatarsal head, heel, lateral malleolus, tibial tubercle, and lateral femoral epicondyle, either directly on the skin or on the shoe surface. An eight-camera motion capture system (VICON, UK) was used to record the coordinates 

of the markers at $120 \mathrm{~Hz}$. Before the test, each subject was instructed to stand still to record the offset position of the ankle joint. The ankle inversion and inversion velocity was calculated by a standard lower extremity biomechanics calculation procedure (Vaughan et al., 1992). The average value of vertical ground reaction force, ankle inversion angle and ankle inversion velocity of the subjects were obtained. The average profiles of the subjects and the peak values of ankle inversion and inversion velocity from these profiles were determined.

\section{Results}

\section{1) Common sporting motion}

The profiles of vertical ground reaction force, ankle inversion angle and ankle inversion velocity during the four common sporting motions are shown in Figure 1. Degree 0 represented the ankle joint position during the steady upright anatomical standing posture. In all motions, there was a sharp ankle eversion (a drop of ankle inversion angle) at the first $0.1 \mathrm{~s}$ after the foot strike. This is also indicated by the sharp peak of ankle eversion velocity (a negative ankle inversion velocity). The ankle was kept in an everted position in correspondence to the offset position during the trimmed stance period for all motions.

The peak values and the time of peak value of the ground reaction force, the ankle inversion angle and the ankle inversion velocity during the four motions are shown in Table 1. For jump-landing and stepping-down, the time of maximum ankle inversion was before the foot strike - this suggests that the ankle everted after foot strike and did not return back to the orientation just before foot strike. The maximum ankle inversion velocity was higher in running $(85.1 \mathrm{deg} / \mathrm{s})$, and was achieved at a time 
103 during late stance. This was to initiate ankle inversion in order to push off the ground

104 to propagate.

105

106 2) Simulated sprain motion

107 The profiles of ankle inversion angle and ankle inversion velocity during the platform

108 fall at different angles are shown in Figure 2. For inversion angle, there were two

109 local peaks during each supination, ranging from $9.9^{\circ}$ to $17.7^{\circ}$ at $0.12-0.16 \mathrm{~s}$. The

110 maximum inversion velocity ranges from 114.0 to $202.5 \mathrm{deg} / \mathrm{s}$ (Table 2). Both

111 inversion angle and velocity were decreasing as the angle of the fall platform 112 increased.

113

114 Discussion

115 The results suggested that the maximum ankle inversion velocity was below $90 \mathrm{deg} / \mathrm{s}$

116 in all common sporting motions. Moreover, the profiles of the ankle inversion velocity

117 (Fig. 1) suggested that the maximum ankle inversion velocity happened at the end of

118 the stance, for the ankle to invert and push off the ground for the next step. This

119 finding, together with the ankle orientation profile, further suggested that ankle

120 inversion does not happen in normal non-injury sport motions. This is in agreement

121 with previous study to show that ankle eversion takes place during the stance time in

122 running (Stacoff et al., 2000). One should note that for the subject with ankle

123 instability, this may not be true since their gait kinematic was altered (Monaghan et al.,

124 2006; Delahunt et al., 2006 \& 2007).

125

126 For the data of simulated sprain motion, there was a general tendency for a decrease

127 of inversion angle with the increase of platform angle. This is because when the 
platform angle increased, the rotating axis of the sprain simulator moved away from the inversion/eversion axis and approached the plantar flexion/dorsiflexion axis of the

130 ankle of the tested subject. There is no much different between the inversion angle of

131 the common sporting motion and simulated sprain motion. However, the inversion

132 velocity of simulated sprain motion is much greater than the common sporting motion.

133 Therefore, inversion velocity can be used to differentiate common sporting motion 134 and sprain motion.

136 A recent case report of an accidental supination ankle sprain injury event reported the

137 ankle biomechanics determined by a multi-view high speed video sequence analysis

138 (Fong et al., 2009b). It suggested that there were two phases, risk-developing phase 139 and injury phase, during sprain injury. During the risk-developing phase, the 140 maximum inversion velocity was $632 \mathrm{deg} / \mathrm{s}$ and the sprain injury has not been induced

141 in this phase. Therefore, it is safe to set the threshold at $300 \mathrm{deg} / \mathrm{s}$. Also, this threshold

142 would not restrict the motion of the ankle since the inversion velocity of the common

143 sporting motion is below $100 \mathrm{deg} / \mathrm{s}$ (Fig. 3). One should note that the threshold 144 suggested here is only based on the preliminary data of single sex and small sample 145 size. In order to extrapolate the results to a wider audience, a further study with larger 146 sample size is needed. Using two tiny inertial and magnetic sensors for ankle

147 kinematics measurement, an in-shoe sensor system could be devised for the 148 identification of significant ankle sprain injury risk.

\section{Conclusion}

151 This study investigated the ankle inversion and inversion velocity during various 152 common motions in sports and simulated sprain motion. Together with the 
153 information reported in the case report of an accidental ankle sprain injury, a threshold

154 ankle inversion velocity of $300 \mathrm{deg} / \mathrm{s}$ was suggested.

155

156 Conflict of interest

157 The authors declare no financial and personal relationships with other people or

158 organizations that could inappropriately influence this submitted work.

159

160 Acknowledgments

161 This research project was made possible by resources donated by The Hong Kong

162 Jockey Club Charities Trust. The Innovation Technology Fund from the Innovation

163 and Technology Commission, Hong Kong Special Administrative Region

164 Government also financially supported the project. (Project Number: ITS/013/07).

165

166 References

167 1. Chan KM, 2006. Ankle injuries in sports - What's new on the horizon? Journal of 168 Medical Biomechanics 21(Supp),6-7.

169 2. Chan YY, Fong DTP, Yung PSH, Fung KY, Chan KM, 2008. A mechanical

170 supination sprain simulator for studying ankle supination sprain kinematics.

$171 \quad$ Journal of Biomechanics 41,2571-2574.

172 3. Delahunt E and Monaghan K, 2006. Altered neuromuscular control and ankle

173 joint kinematics during walking in subjects with functional instability of the

$174 \quad$ ankle joint. The American Journal of Sports Medicine 34,1970-1976.

175 4. Delahunt E, Monaghan K, Caulfied B, 2007. Ankle function during hopping in

176 subjects with functional instability of the ankle joint. Scandinavian Journal of

177 Medicine and Science in Sports 17,641-648. 
5. Fong DTP, Chan YY, Mok KM,Yung PSH, Chan KM, 2009a. Understanding acute ankle ligamentous sprain injury in sports. Sports Medicine, Arthroscopy, Rehabilitation, Therapy \& Technology 1:14.

6. Fong DTP, Hong Y, Chan LK, Yung PSH, Chan KM, 2007a. A systematic review on ankle injury and ankle sprain in sports. Sports Medicine 37,73-94.

7. Fong DTP, Hong Y, Li JX, 2007b. Cushioning and lateral stability functions of cloth sport shoes. Sports Biomechanics 6,407-417.

8. Fong DTP, Hong Y, Shima Y, Krosshaug T, Yung PSH, Chan KM, 2009b. Biomechanics of supination ankle sprain - a case report of an accidental injury event in laboratory. The American Journal of Sports Medicine 37,822-827.

9. Fong DTP, Man CY, Yung PSH, Cheung SY, Chan KM, 2008. Sport-related ankle injuries attending an accident and emergency department. Injury $39,1222-1227$.

10. Krips R, de Vries J, van Dijk CN, 2006. Ankle instability. Foot and Ankle Clinics of North America 11,311-329.

11. Monaghan K, Delahunt E, Caulfield B, 2006. Ankle function during gait in patients with chronic ankle instability compared to controls. Clinical Biomechanics 21,168-174.

12. O'Donovan KJ, Kamnik R, O'Keeffe DT, Lyons GM, 2007. An inertial and magnetic sensor based technique for joint angle measurement. Journal of Biomechanics 40,2604-2611.

13. Stacoff A, Nigg BM, Reinschmidt C, van den Bogert AJ, Lundberg A, 2000. Tibiocalcaneal kinematics of barefoot versus shod running. Journal of Biomechanics 33,1387-1395.

14. Vaughan CL, Davis BL, O'Conner JC, 1992. Dynamics of Human Gait: Human 


\section{Figure legends}

206 Figure 1 - The profiles of (a) vertical ground reaction force, (b) ankle inversion angle 207 and (c) ankle inversion velocity during the four common sporting motions performed 208 in this study. A negative ankle inversion angle means that the ankle is everted in correspondence to the offset position. A negative inversion velocity means that the ankle is performing eversion. Dotted lines indicate one standard deviation from the

211 mean.

212 Figure 2 - The profiles of (a) ankle inversion angle and (b) ankle inversion velocity 213 during the simulated sprain motions performed in this study. A negative ankle 214 inversion angle means that the ankle is everted in correspondence to the offset 215 position. A negative inversion velocity means that the ankle is performing eversion.

216 Figure 3 - Mean and standard deviation of peak value of inversion velocity. Dotted

217 line is the threshold suggested.

219 Table 1 - The peak values and the time of peak value of the ground reaction force, the 220 ankle inversion angle and the ankle inversion velocity during the four common 221 sporting motions.

\begin{tabular}{|l|c|c|c|c|}
\hline & Running & Cutting & Jump-landing & Stepping-down \\
\hline Peak VGRF (N) & 1648.8 & 1151.0 & 1882.8 & 1832.2 \\
\hline Peak VGRF (Body weight) & 2.39 & 1.66 & 2.72 & 2.66 \\
\hline Time of peak VGRF (s) & 0.08 & 0.02 & 0.05 & 0.05 \\
\hline * Max ankle inversion (deg) & -16.4 & -2.9 & -8.0 & -25.2 \\
\hline ** Time of max ankle inversion (s) & 0.06 & 0.15 & 0.19 & 0.19 \\
\hline Max ankle inversion velocity (deg/s) & 85.1 & 37.2 & 22.5 & 70.1 \\
\hline
\end{tabular}




\begin{tabular}{|l|l|l|l|l|}
\hline$* *$ Time of max ankle inversion velocity (s) & 0.16 & -0.04 & 0.13 & 0.56 \\
\hline
\end{tabular}

* Negative value in maximum ankle inversion means that the ankle was in an everted position relative

223 to the offset position.

$224 * *$ Negative time means that the time was before the moment of foot strike.

225

226 Table 2 - The peak values and the time of peak value of the ankle inversion angle and

227 the ankle inversion velocity during the five simulated sprain motions.

\begin{tabular}{|l|c|c|c|c|c|}
\hline Platform angle (deg) & 0 & 23 & 45 & 67 & 90 \\
\hline Max ankle inversion (deg) & 17.7 & 15.4 & 13.5 & 11.8 & 9.9 \\
\hline Time of max ankle inversion (s) & 1.0 & 0.12 & 0.15 & 0.30 & 0.13 \\
\hline Max ankle inversion velocity (deg/s) & 202.5 & 158.7 & 149.5 & 118.6 & 114.0 \\
\hline Time of max ankle inversion velocity (s) & 0.07 & 0.07 & 0.08 & 0.09 & 0.05 \\
\hline
\end{tabular}




\section{Common Sporting Motion}

(a) Vertical ground reaction force
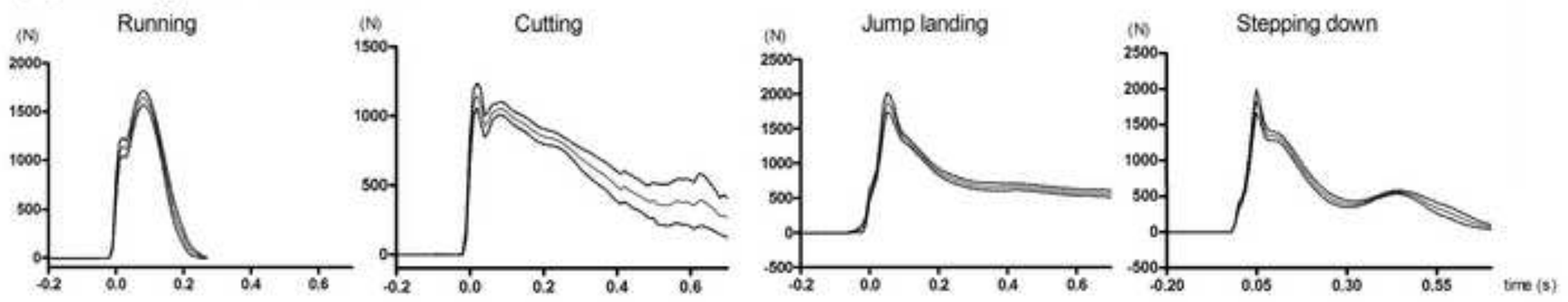

(b) Inversion angle
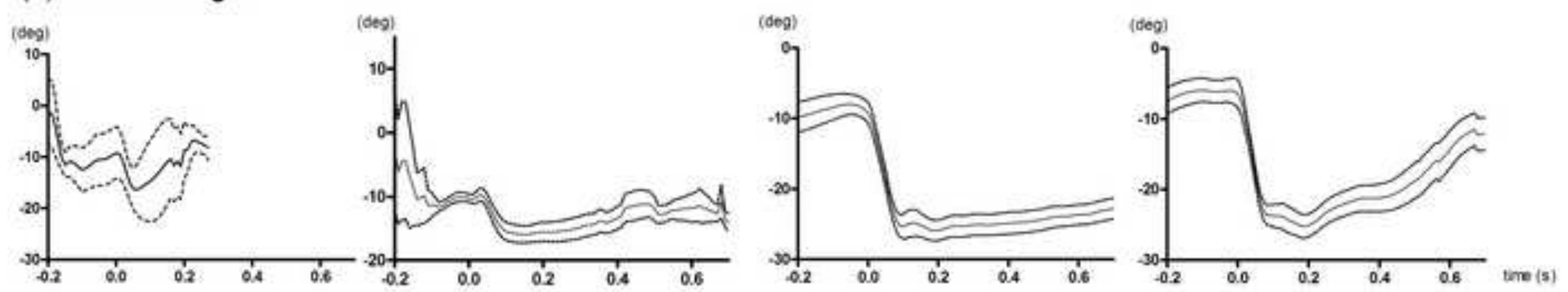

\section{(c) Inversion velocity}
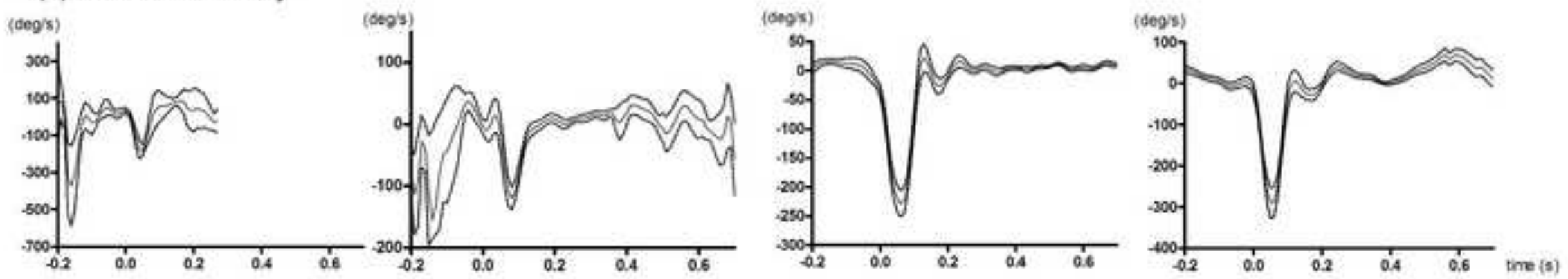
Figure 2

Click here to download high resolution image

Simulated sprain motion

(a) Average Inversion Angle
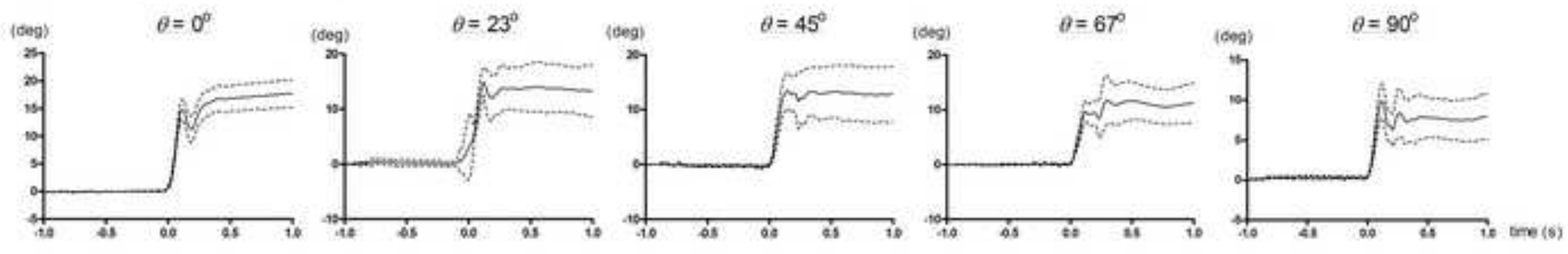

(b) Average Inversion Velocity
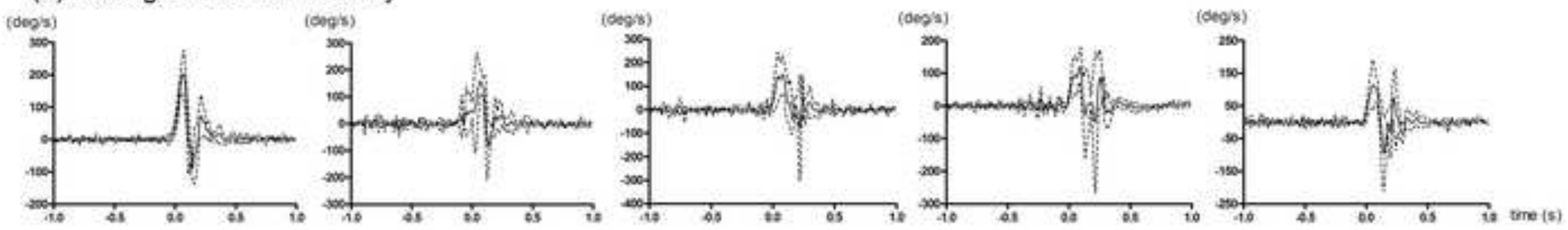


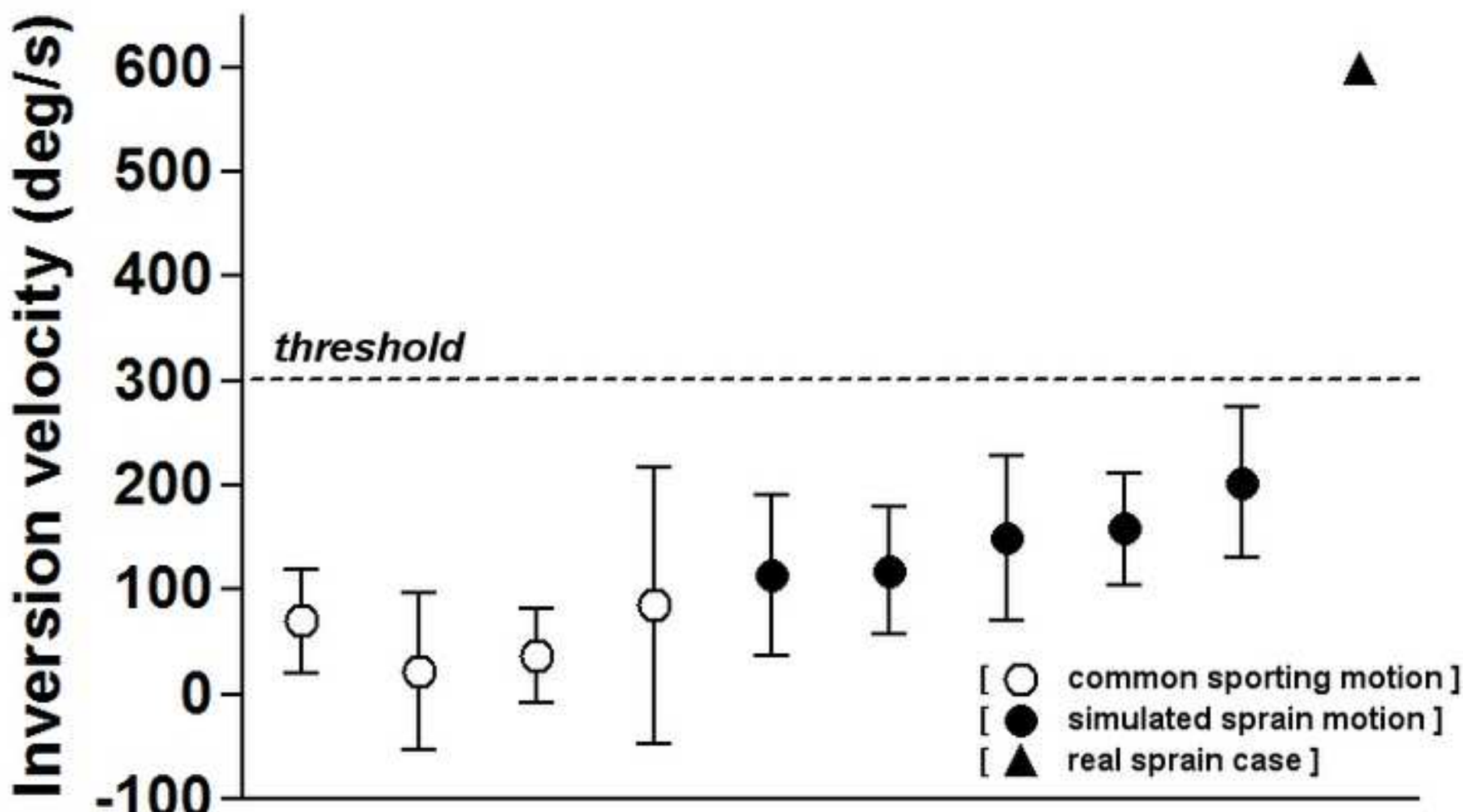




\section{Conflict of interest}

Dear Editor of Journal of Biomechanics,

REF: Submission of manuscript titled "Differentiation of ankle sprain motion and common sporting motion by ankle inversion velocity".

The authors declare no financial and personal relationships with other people or organizations that could inappropriately influence this submitted work.

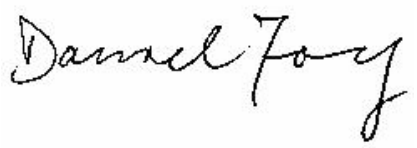

Daniel Tik-Pui FONG

Mar 11th, 2010. 